This is the peer reviewed version of the following article: Journal of the Science of Food and Agriculture (2018), which has been published in final form at https://doi.org/10.1002/jsfa.9012. This article may be used for non-commercial purposes in accordance with Wiley Terms and Conditions for Self-Archiving

\title{
Concentrates of triterpenic acids obtained from crude olive pomace oils: characterization and evaluation of their potential antioxidant activity
}

\author{
Joaquín Velasco, ${ }^{1, *}$ Francisca Holgado, ${ }^{2}$ Gloria Márquez-Ruiz ${ }^{2}$ and M. Victoria Ruiz- \\ Méndez ${ }^{1}$ \\ ${ }^{1}$ Instituto de la Grasa, Consejo Superior de Investigaciones Científicas (CSIC), \\ Campus Universidad Pablo de Olavide, Ctra. de Utrera Km 1, E-41013 Sevilla, Spain \\ ${ }^{2}$ Instituto de Ciencia y Tecnología de Alimentos y Nutrición, Consejo Superior de \\ Investigaciones Científicas (CSIC), c/ José Antonio Novais, 10, E-28040 Madrid, Spain
}

*To whom correspondence should be addressed:

Telephone: +34954611550

Fax: $\quad+34954616790$ 
E-mail: jvelasco@ig.csic.es 


\section{Abstract}

\section{BACKGROUND}

3 Pentacyclic triterpenic acids (TA) are phytochemicals of increasing nutritional interest due to

4 their bioactive properties, such as anti-inflammatory, anti-tumoral, anti-hyperglycemic,

5 hepatoprotective and others. Crude olive pomace oils constitute a non-exploited significant

6 source of these compounds. In the present study, concentrates of TA were extracted and

7 characterized from crude olive pomace oils that were obtained by centrifugation and

8 subsequent solvent extraction, respectively. Specifically, the concentrates were obtained from

9 the byproduct generated in the filtration of the oils. The solids were subjected to Soxhlet 10 extractions with hexane to remove the residual oil and then with ethanol for the TA 11 extraction.

\section{RESULTS}

13 Concentrates containing 850-980 $\mathrm{g} \mathrm{kg}^{-1}$ TA were isolated from the oils obtained by 14 centrifugation, whereas those isolated from oils obtained by hexane extraction presented 15 levels of TA that ranged from 510 to $900 \mathrm{~g} \mathrm{~kg}^{-1}$. Oleanolic (OA) and maslinic (MA) acids 16 were the TA found in the concentrates. The relative contents of OA and MA were, 17 respectively, 30:70 (p/p) and 77:23 (p/p). All concentrates also presented phenolic compounds 18 at levels of $\mathrm{g} \mathrm{kg}^{-1}$ and displayed slight antioxidant properties. CONCLUSION

20 Concentrates of TA, containing MA and OA, can be readily obtained from a byproduct 21 generated by filtration of crude olive pomace oils. Concentrates isolated from oils obtained by 22 centrifugation were rich in MA, whereas those from oils extracted with hexane were rich in 23 OA. The concentrates showed slight antioxidant properties that can be mainly attributed to the 24 presence of phenolic compounds and not to TA. 
26 Key-words: Triterpenic acids; oleanolic; maslinic; olive pomace oil, by-product reutilization 
The industrial production of olive oil in Spain is commonly carried out by applying a twophase centrifugation system that, apart from the oil, generates a semisolid byproduct called two-phase pomace or "alperujo". In this byproduct, there is still a considerable amount of residual oil that is normally extracted by solvent extraction with hexane. The generation of "alperujo" is so concentrated in time that this has to be stored in large ponds, in which it remains in the open air for months, and the oil is extracted periodically. Before storage, part of the residual oil is separated by a three-phase centrifugation system. The stored "alperujo" is dried by a drastic process and the remaining oil is extracted with hexane. As a result, two crude olive pomace oils are obtained by centrifugation and subsequent solvent extraction from "alperujo". 1,2 In practice, the two oils are mixed and the blend is refined, though they are more and more often used separately.

Apart from the residual oil, "alperujo" also contains significant amounts of valuable bioactive compounds that pass in part to the oil extracted. ${ }^{3}$ Such is the case of triterpenic acids (TA), a group of pentacyclic compounds of increasing nutritional interest. Numerous beneficial health properties have been attributed to TA, such as anti-inflammatory, anti-tumoral, antihyperglycemic, hepatoprotective, cardioprotective and antimicrobial effects. ${ }^{4-7}$ Oleanolic and maslinic acids are the main TA found in olive oils and olive pomace oils. ${ }^{2}$ While minor amounts of these compounds are detected in olive oils, significant concentrations occur in olive pomace oils, and especially in crude oils, in which are mostly present as solid particles in suspension because of their very low solubility. Concentrations of almost $8000 \mathrm{mg} \mathrm{kg}^{-1}$ of maslinic and oleanolic acid, respectively, have been detected in crude pomace oils obtained by centrifugation, ${ }^{2}$ whereas the concentration of TA in virgin olive oils has been reported to be lower than $100 \mathrm{mg} \mathrm{kg}^{-1}$ oil. $^{8}$ Therefore, crude pomace oils represent a good source of these 51 valuable compounds. 
Along with the free fatty acids, TA and other phytochemicals are substantially removed in the conventional refining process with caustic soda. ${ }^{9}$ In this regard, our research group has patented a technological approach to increase the levels of TA in edible olive pomace oil obtained by centrifugation. ${ }^{10}$ Relatively high amounts of TA are retained in the oil by applying a specific physical refining in which the free fatty acids are removed by successive distillation steps. Previous to refining, the crude oil is filtered leaving a byproduct that can be utilized as raw material to obtain concentrates of TA. Obtaining these concentrates is also the objective of the mentioned patent. The byproduct generated in the filtration step is subjected to a soxhlet extraction with hexane to remove the remaining oil and, subsequently, to a second soxhlet extraction with ethanol to obtain concentrates of TA.

Some of the positive effects of TA against certain diseases have been attributed in part to their antioxidant properties. TA have shown inhibition of lipid peroxidation in rat liver microsomes, ${ }^{11-13}$ protection against oxidative damage in $\mathrm{DNA}^{14}$ and in low-density lipoproteins (LDL), ${ }^{12,15}$ and inhibition of cyclo-oxygenase and 5-lipoxygenase activities. ${ }^{16}$ Despite the claimed antioxidant properties, a few studies have shown contradictory results. Oleanolic acid did not show free radical scavenging activity by the oxygen radical absorbance capacity (ORAC) assay, whereas maslinic acid acted as an efficient peroxyl radical scavenger. ${ }^{14,15}$ Castellano et al. ${ }^{17}$ found a low activity of oleanolic acid in scavenging the ABTS radical, i.e. 2,2'-azinobis(3ethylbenzothiazoline-6-sulfonic acid), no activity in capturing the DPPH radical, i.e. 2,2-diphenyl-1-picrylhydrazyl, and very low activity in protecting fluorescein in the ORAC assay. They even found that oleanolic acid not only did not prevent oxidation of olive oil at Rancimat conditions but otherwise showed a pro-oxidant effect. The pro-oxidant effect was also evident in refined sunflower oil and this was much higher than that found in the olive oil. 
The aim of this study was obtaining and characterizing concentrates of TA from crude olive pomace oils obtained by centrifugation and subsequent solvent extraction, respectively. To the best of our knowledge, concentrates from oils obtained by solvent extraction have not been undertaken so far. Furthermore, due to the controversy concerning the antioxidant activity of TA, the antioxidant activity of the concentrates was explored. For this purpose, the free radical scavenging activities to DPPH and ABTS, to peroxyl radicals in the ORAC assay and the ferric reducing/antioxidant power (FRAP) were studied.

\section{MATERIALS AND METHODS}

\section{Chemicals}

Oleanolic acid $(\geq 97 \%)$, maslinic acid $(\geq 98 \%)$, Trolox (97\%), tert-butylhydroxytoluene (BHT) ( $\geq 99 \%),( \pm)-\alpha$-tocopherol $(\geq 96 \%)$, DPPH, ABTS, 2,4,6-tris(2-pyridyl)-s-tirazine (TPTZ) ( $\geq \quad 99 \%), \quad$ ferric chloride hexahydrate, fluorescein and 2,2azobis(methylpropionamidine)dihydro (APPH) were acquired from Sigma-Aldrich (Madrid, Spain). $\quad N, O$-bis(trimethylsilyl)trifluoroacetamide $\quad$ (BSTFA) containing $1 \%$ trimethylchlorosilane (TMCS), used as silylation reagent, was purchased from Supelco (Bellefonte, PA, USA).

\section{Oil samples and treatments}

Twelve crude olive pomace oils obtained by centrifugation or by subsequent solvent extraction were supplied in 1-L bottles by "Oleícola El Tejar" (Córdoba, Spain). The oils were produced in two consecutive seasons. Specifically, the oils were obtained in January, April and May 2013 (2012/2013 season), and in December 2013, March and June 2014 (2013/2014 season). While the oils of the second season were used immediately as they were received, the oils of the first season had been stored for one year at $5{ }^{\circ} \mathrm{C}$ when they were filtered. About $800 \mathrm{~g}$ oil were filtered in the lab using a filter paper. The filtration was carried 
out at room temperature. Previously, the oils were homogenized by shaking manually their

101 corresponding bottles. The filtration process lasted about 3 days. The content of the filter 102 paper was subjected to soxhlet extraction. First, hexane was used to remove the oil and,

103 second, ethanol to extract TA. The soxhlet comprised a 1-kg solid container and a 5-L liquid

104 flask. The extraction processes with hexane and ethanol were performed during 4 and $8 \mathrm{~h}$,

105 respectively. The solvent of the ethanolic extract was evaporated in a rotary evaporator at 70

$106{ }^{\circ} \mathrm{C}$ and finally in a vacuum oven at $70{ }^{\circ} \mathrm{C}$ and 50 mbar until a concentrate in dry powder form 107 was obtained at constant weight. The concentrates obtained from oils produced by

108 centrifugation were named C samples, whereas those from oils extracted with solvent were

109 referred to as $\mathrm{S}$ samples. All samples were stored in a refrigerator at $5{ }^{\circ} \mathrm{C}$ until analysis.

\section{Analysis of triterpenic acids}

111 The concentrations of TA in the concentrates were analyzed by HPLC according to García et

$112 \mathrm{al}^{2}$ A volume of $20 \mu \mathrm{L}$ of a solution of the concentrates in ethanol at $0.5 \mathrm{mg} / \mathrm{mL}$ was

113 analyzed directly in a chromatograph equipped with a Waters 717 plus autosampler, a Waters

114600 pump, a Waters column heater module and a Waters 996 photodiode array detector

115 whose data were recorded and processed in Empower.2 software (Waters, Inc., Milford, MA,

116 USA). A Spherisob ODS-2 column (Waters, Inc.) $(25 \mathrm{~cm} \times 4.6 \mathrm{~mm}$ i.d., $5 \mu \mathrm{m}$ particle size $)$

117 was used. The separations were performed at $35{ }^{\circ} \mathrm{C}$ in isocratic regime using

118 methanol:acidified water with phosphoric acid $(\mathrm{pH} 3.0)(92: 8, \mathrm{v} / \mathrm{v})$ at a flow rate of $0.8 \mathrm{~mL}$

$119 \min ^{-1}$. TA were detected at $210 \mathrm{~nm}$ and quantified using external calibration. 


\section{HPSEC analysis}

122 The concentrate samples were dissolved in tetrahydrofuran at $20 \mathrm{mg} \mathrm{mL}^{-1}$ and filtered through

123 a $0.22 \mu \mathrm{m}$ pore size PTFE filter. While the $\mathrm{C}$ samples were completely dissolved in

124 tetrahydrofuran, the $\mathrm{S}$ samples presented fines in suspension. A volume of $10 \mu \mathrm{L}$ of the

125 filtered solutions were analyzed in an HPSEC chromatograph equipped with an AT 1100

126 autosampler (Agilent Technologies, Palo Alto, CA), a Knauer 120 HPLC pump (Knauer,

127 Berlin, Germany) and a Merck L-7490 refractive index detector (Merck, Darmstadt,

128 Germany). The separation was performed on two 100 and $500 \AA$ Altrastyragel columns (25

$129 \mathrm{~cm} \times 0.77 \mathrm{~cm}$ i.d., $5 \mu \mathrm{m}$ particle size) packed with porous, highly cross-linked styrene-

130 divinylbenzene copolymers (Agilent Technologies, Palo Alto, CA) connected in series.

131 Tetrahydrofuran at a flow rate of $1 \mathrm{~mL} / \mathrm{min}$ was the mobile phase. The relative concentrations

132 of the different components were estimated considering the same response factor for all the

133 analytes.

\section{GC-MS analysis}

135 The TA samples were derivatized by applying a silylation reaction prior to the CG-MS 136 analysis. A volume of $300 \mu \mathrm{L}$ of the silylation reactant, BSTFA containing $1 \%$ of TMCS, was

137 added to an aliquot of $10 \mathrm{mg}$ of TA concentrates. The reaction was performed at $100{ }^{\circ} \mathrm{C}$ for $13830 \mathrm{~min}$. Then the solution was directly analyzed by GC-MS. A Finnigan Trace-GC 2000 gas

139 chromatograph coupled to a Polaris-Q Ion trap mass spectrometer (ThermoFinnigan, Austin,

140 TX, USA) operating in full scan and the MS/MS mode was used. The chromatograph was 141 equipped with a split/splitless injector that operated at $285^{\circ} \mathrm{C}$ in the split mode with a $20: 1$

142 split ratio. The column used was a Zebron ZB-5ms (Phenomenex, Torrance, CA, USA) fused 143 silica capillary column $(30 \mathrm{~m}$ long $\times 0.25 \mathrm{~mm}$ i.d $\times 0.25 \mu \mathrm{m}$ film thickness $)$. Helium at 1 $144 \mathrm{~mL} / \mathrm{min}$ at constant flow was the carrier gas. The initial temperature was $150{ }^{\circ} \mathrm{C}$, which was 145 kept for $5 \mathrm{~min}$, then raised to $290{ }^{\circ} \mathrm{C}$ at a rate of $5{ }^{\circ} \mathrm{C} / \mathrm{min}$ and held for $50 \mathrm{~min}$. The electron 
146 energy applied was $70 \mathrm{eV}$ and the scan range used was 60-700 amu. The Xcalibur software

147 (version 1.4) was used for data acquisition and processing.

\section{Analyses of antioxidant properties}

149 A Synergy ${ }^{\mathrm{TM}}$ HT-multimode microplate reader with an automatic reagent dispenser and a 150 temperature controller from Biotek Instruments (VT, USA) was used in the different 151 antioxidant assays. Biotek Gen5 ${ }^{\mathrm{TM}}$ data analysis software was used. Each 96-well plate was

152 designed to assay four repetitions per sample and standard, four levels of standards for 153 calibration, and eight repetitions per blank or control. The reactions were initiated by 154 automatic addition of $60 \mu \mathrm{L}$ of the reactant solutions in the DPPH, ABTS, FRAP and ORAC assays, respectively. In all assays, two different solutions of the TA samples were measured.

156 First, a solution was made by adding to $100 \mathrm{mg}$ of sample $10 \mathrm{~mL}$ of an acid ethanolic solution

157 prepared with ethanol, water and $2 \mathrm{M} \mathrm{HCl}$ at a relative proportion of 1:1:0.02 (v/v). The 158 solution was shaken in a vortex for $20 \mathrm{~min}$, centrifuged at $5000 \mathrm{rpm}$ for $20 \mathrm{~min}$ and the 159 solvent was separated. The procedure was repeated again by adding $4 \mathrm{~mL}$ of the ethanolic 160 solution to the precipitate. Both ethanolic phases were joined and measured. The other 161 solution tested was that prepared by dissolving the concentrates in absolute ethanol at a

162 concentration of $0.5 \mathrm{mg} \mathrm{mL}^{-1}$. All samples were completely dissolved at this concentration.

163 The results obtained with the two solutions were not different between each other. Results of 164 the second solution were presented only. Pure maslinic acid and oleanolic acid dissolved at $1650.5 \mathrm{mg} / \mathrm{mL}$ in absolute ethanol were also tested. In addition, BHT and $\alpha$-tocopherol dissolved 166 in absolute ethanol were also measured as reference antioxidants.

167 DPPH assay

168 The procedure used was that described by Morales et al. ${ }^{18} \mathrm{DPPH}$ absorption decay was recorded at $520 \mathrm{~nm}$ for $10 \mathrm{~min}$. The antiradical activity was determined at $10 \mathrm{~min}$ and this was 
expressed as Trolox equivalent antioxidant capacity (TEAC) using a calibration curve with

171 Trolox solutions in absolute ethanol at concentrations of 40, 100, 200 and $400 \mu \mathrm{M}$. All the

172 reaction mixtures were prepared in duplicate and four independent assays were run for each

173 sample. The limit of quantification was $10 \mu \mathrm{M}$.

$174 \quad$ ABTS assay

175 The free radical scavenging activity was also evaluated against the ABTS radical cation,

176 according to Morales et al. ${ }^{18}$ with minor modifications. The ABTS radical was measured at

$177734 \mathrm{~nm}$ and data were recorded for $10 \mathrm{~min}$. The antiradical activity was also determined at 10

178 min and expressed as TEAC using a calibration curve with Trolox dissolved in absolute

179 ethanol. All the reaction mixtures were prepared in duplicate and four independent assays

180 were run for each sample. The limit of quantification was $40 \mu \mathrm{M}$.

FRAP assay

182 The ferric reducing ability was determined according to Morales et al. ${ }^{18}$ It was based on the

183 reduction reaction of the $\mathrm{Fe}^{3+}-\mathrm{TPTZ}$ complex to the $\mathrm{Fe}^{2+}$ form under acidic conditions, which

184 generates an intense blue color with a maximum light absorption at $595 \mathrm{~nm}$. Only the samples

185 prepared in the acidified ethanolic solution were measured. Similar to the DPPH and ABTS

186 assays, the ferric reducing ability was expressed as TEAC using a calibration curve with

187 Trolox. All the reaction mixtures were prepared in duplicate and four independent assays

188 were run for each sample. The limit of quantification was $10 \mu \mathrm{M}$.

ORAC assay

190 The peroxyl radical scavenging activity was determined by applying the ORAC assay also

191 described by Morales et al. ${ }^{18}$ Fluorescein oxidation was induced by the water soluble azo

192 initiator APPH at $37^{\circ} \mathrm{C}$. The reaction was carried out in a $75 \mathrm{mM}$ phosphate buffer at $\mathrm{pH} 7.4$.

193 The fluorescence decay of fluorescein was recorded for $90 \mathrm{~min}$ using 485 and $528 \mathrm{~nm}$ as 
194 excitation and emission wavelengths, respectively. The radical scavenging activity was

195 determined using the data recorded at $90 \mathrm{~min}$. All the reaction mixtures were prepared in 196 duplicate, and four independent assays were performed for each sample. The antiradical 197 activity was also expressed as TEAC using a calibration curve with Trolox dissolved in water.

198 The limit of quantitation was $5 \mu \mathrm{M}$.

199 Analysis of phenolic compounds

200 The analysis of phenolic compounds was made according to Romero et al. ${ }^{19}$ A volume of 20 $201 \mu \mathrm{L}$ of a solution of the concentrates in ethanol at $20 \mathrm{mg} / \mathrm{mL}$ was analyzed directly in the same 202 HPLC chromatograph described above for the analysis of TA. Phenolic compounds were also 203 separated onto the same HPLC column at $35{ }^{\circ} \mathrm{C}$ using a gradient elution with water $(\mathrm{pH} 2.5$ 204 adjusted with $0.15 \%$ phosphoric acid) (A) and methanol (B). The initial composition was $90 \%$ $205 \mathrm{~A}$ and $10 \% \mathrm{~B}$. The concentration of B was increased to $30 \%$ in $10 \mathrm{~min}$ and held for $20 \mathrm{~min}$. 206 Then, B was raised to $40 \%$ in a period of $10 \mathrm{~min}$, held for $5 \mathrm{~min}$, and then increased to $50 \%$. 207 Finally, B was increased to 60,70 and $100 \%$ in 5-min periods. The initial conditions were 208 reached in $10 \mathrm{~min}$. Chromatograms were recorded at 280 and $240 \mathrm{~nm}$ for phenolic and 209 oleosidic compounds, respectively. Quantification was obtained by external calibration.

\section{Statistical analysis}

211 Unless indicated, analytical determinations were carried out in triplicate and results were 212 expressed as mean values followed by the standard deviation. Comparisons between extracts 213 obtained from oils produced in the same period were made by Student's $t$ test in Microsoft 214 Excel 2010 (Microsoft Corporation, Redmond, WA, USA). A multivariate general linear 215 model (GLM) in 24.0 SPSS Statistics program (SPSS Inc., Chicago, IL, USA) was applied to 216 examine possible significant differences between samples extracted from oils obtained by centrifugation and subsequent hexane extraction. The season, harvest period and type of oil 
were considered the independent factors, whereas the data obtained in the different

219 antioxidant tests, the total content of phenols and the content of $o$-diphenols were the

220 dependent factors. Due to the fact that the null hypothesis in the variance homogeneity test or

221 Levene's test was not fulfilled, a non-parametric test was also applied in the SPSS program.

222 The U test of Mann-Whitney considering independent samples was the test used. Linear 223 correlation analysis was applied in Microsoft Excel 2010 (Microsoft Corporation, Redmond, 224 WA, USA) to determine correlations between the antioxidant tests and the contents of 225 phenolic compounds. Significance was defined at $p<0.05$.

\section{RESULTS AND DISCUSSION}

\section{Extraction and characterization of TA concentrates}

228 The extraction yield of TA was much greater from the oils obtained by centrifugation than

229 those obtained by subsequent solvent extraction. It ranged between 2.5 and $48.4 \mathrm{~g} \mathrm{~kg}^{-1}$ oil in 230 the $\mathrm{C}$ samples and between 1.2 and $3.0 \mathrm{~g} \mathrm{~kg}^{-1}$ oil in the $\mathrm{S}$ samples (Table 1). The lower yields 231 found from the oils obtained by solvent extraction were consistent with the lower amounts of 232 TA reported in crude oils. ${ }^{2}$ This fact was attributed to two fundamental reasons. First, after the 233 oil extraction by centrifugation, the TA levels in the "alperujo" decreased because a great part 234 was removed along with the oil. Second, the low solubility of TA in hexane also contributed 235 to a lower amount of these compounds in the oils extracted with solvent compared to those 236 obtained previously by centrifugation. ${ }^{2}$

237 The amount of extract from the $\mathrm{C}$ oils increased along the season period in the two seasons 238 studied, whereas no pattern was found for the S samples. This fact was coherent with the 239 increase of TA observed in the oil phase of "alperujo" during its storage time in large ponds 240 in a previous study. ${ }^{2}$ 
The analysis of TA in the concentrates showed the presence of oleanolic and maslinic acids in

242 high amounts (Table 2). With the exception of sample 6, the total levels of TA were 243 substantially greater for the $\mathrm{C}$ samples. These ranged between 850 and $980 \mathrm{~g} \mathrm{~kg}^{-1}$ for the C 244 samples and between 510 and $900 \mathrm{~g} \mathrm{~kg}^{-1}$ for the $\mathrm{S}$ samples. Clear differences were also 245 observed in the TA composition between the C and S samples. While the most abundant TA 246 in the $\mathrm{C}$ samples was maslinic acid (MA), showing concentrations that varied between 575 247 and $698 \mathrm{~g} \mathrm{~kg}^{-1}$ sample, oleanolic acid (OA) was predominant in the $\mathrm{S}$ samples, with 248 concentrations that ranged between 405 and $703 \mathrm{~g} \mathrm{~kg}^{-1}$ sample. On average, the relative concentrations of OA and MA were, respectively, 30:70 (p/p) for the C samples and 77:23 (p/p) for the S samples. Therefore, concentrates rich in MA and OA, respectively, were obtained from the oils extracted by centrifugation and subsequent extraction with hexane. In this respect, results reported for crude olive pomace oils also showed higher amounts of MA than OA in oils obtained by centrifugation and the opposite was true for the oils obtained by

254 subsequent extraction with hexane. ${ }^{2}$ However, the relative concentrations of OA and MA were different to those found in the present study for the concentrates. On average, the relative concentrations of OA and MA were reported to be, respectively, 43:45 (p/p) for the oils extracted by centrifugation and $87: 13(\mathrm{p} / \mathrm{p})$ for those obtained by solvent extraction. ${ }^{2}$ The higher concentration of $\mathrm{OA}$ in the oils extracted with solvent was mainly attributed to its greater solubility in hexane than MA. Similarly, the great solubility differences in hexane between OA and MA could also explain the much higher relative concentration of MA found

261 for the C samples in the present study compared to the values reported in oils. ${ }^{2}$ In this regard, 262 substantial amounts of OA could have been removed in the washing step with hexane before 263 the extraction of TA with ethanol.

264 An HPSEC analysis was applied first to gain an insight about what type of compounds other than TA were present in the concentrates. This is the analysis used in the evaluation by 
molecular weight of the groups of compounds that form the polar fraction of used frying oils. ${ }^{20}$ HPSEC chromatograms showed the presence of tri-, di- and mono-acylglycerols, apart from TA, which eluted as a single chromatographic peak (not shown). The sum of tri-, di- and mono-acylglycerols was used as an estimate of the amount of residual oil in the concentrates (Table 3). Samples $1 \mathrm{~S}$ and 6C showed amounts of oil as high as 240 and $108 \mathrm{~g} \mathrm{~kg}^{-1}$ sample, 271 respectively, which indicated an inefficient wash with hexane. The amount of residual oil 272 varied between 10 and $70 \mathrm{~g} \mathrm{~kg}^{-1}$ for the rest of samples. The results for samples $1 \mathrm{~S}$ and $6 \mathrm{C}$ were coherent with their relatively low values of TA (Table 2). However, the amount of residual oil did not explain the relatively low values of TA in a few samples, such as sample $4 \mathrm{~S}$, which presented an oil content of $10 \mathrm{~g} \mathrm{~kg}^{-1}$ sample only. This fact suggested that the concentrates also comprised compounds that eluted along with the TA in the HPSEC analysis.

A GC-MS analysis of the concentrate samples derivatized with TMSi exhibited the presence of free fatty acids and confirmed the occurrence of monoacylglycerols (not shown). The fatty acids detected were palmitic, oleic, linoleic and linolenic acids. The free fatty acids were therefore compounds that eluted along with the TA in the HPSEC analysis. Although not observed in the GC-MS analysis, other compounds that could be present in the concentrates 282 of TA because of their polarity could be aliphatic alcohols. These form part of the minor 283 fraction in crude olive pomace oils and are present at substantial amounts. ${ }^{2}$ In a previous study, the concentrations of aliphatic alcohols detected in crude olive pomace oils obtained by hexane extraction were substantially greater than those determined in their corresponding oils produced by previous centrifugation. ${ }^{2}$ If present, similarly to free fatty acids, aliphatic 287 alcohols would also elute along with TA in the HPSEC analysis and also would contribute to 288 the less purity found for the S samples.

\section{Evaluation of the potential antioxidant activity of TA concentrates}


All concentrates showed antiradical activity towards DPPH and ABTS (Figure 1A).

291 Compared to chain-breaking antioxidants like $\alpha$-tocopherol and BHT, the antiradical

292 activities of the concentrates found in the two tests were two orders of magnitude lower (data 293 not shown). The activity values in the DPPH test were similar for each pair of C and S 294 samples, although slight significant differences were detected when analyzing the mean 295 values individually. A global analysis of all samples did not show a definite pattern. In fact, a 296 non-parametric test did not show significant differences between the C and S samples. Similar 297 results were also found in the ABTS test.

298 Despite the antiradical activity found in the concentrates, pure OA and pure MA did not 299 display activity in the DPPH test at the same experimental conditions. MA did not either show 300 antiradical activity towards ABTS, whereas OA exhibited certain activity that was low (10 $301 \mu \mathrm{mol} / \mathrm{g}$ TEAC) but comparable to the concentrates that showed the lowest values (Figure 1A).

The DPPH and ABTS tests also provided values with a decreasing trend as the season 303 progressed in each harvest. In addition, an increased antiradical activity was also observed in 304 the second season compared to the first one.

305 The TA concentrates also showed ferric reducing power and the results obtained were not 306 different to those of the antiradical activity tests (Figure 1B). The TEAC values were two 307 orders of magnitude lower than those found for $\alpha$-tocopherol and BHT. While the S samples 308 in the first season displayed significantly greater reducing power than their $\mathrm{C}$ sample 309 homologs, a definite pattern was not found in the following harvest. With the exception of the

310 S samples in the first harvest, it was also observed that the reducing power decreased as the 311 season progressed. Also, the concentrates obtained from the oils of the second harvest 312 generally showed on average greater values. Pure MA and OA did not either present ferric 313 reducing power. 
314 The TA concentrates also presented antiradical activity in the ORAC assay (Figure 1C).

315 Although significant differences were found between the $\mathrm{S}$ and $\mathrm{C}$ samples obtained from oils

316 of a given period, a definite pattern along each season was not observed. A clear trend of

317 activity losses along a harvest was not found, but greater activity on average was detected in

318 the second harvest compared to the previous one. Pure MA and OA displayed very slight

319 antioxidant activity, which was from one to two orders of magnitude less than the activities

320 found for the TA concentrates.

321 The results obtained in the different tests for pure OA agreed with those reported by

322 Castellano et al. ${ }^{17}$ These authors found that OA showed no activity in inhibiting the DPPH

323 radical, a low activity in scavenging the ABTS radical, and very low activity in protecting

324 fluorescein in the ORAC assay. In contrast, Allouche et al. ${ }^{14}$ did observe radical scavenging

325 activities for both OA and MA in the DPPH and ABTS tests, but these were very weak and 326 dependent on the TA concentrations. In fact, a high DPPH scavenging activity was found for

327 MA when its concentration was 5 mol per mol of DPPH or higher. Therefore, the results of

328 the antioxidant tests seem to be dependent on the experimental conditions and, for this reason,

329 discrepancies between different studies could be justified. ${ }^{21}$ The antioxidant role attributed to

330 TA in numerous pathological processes goes, however, beyond the very weak antiradical 331 activity observed through tests that are even subjected to experimental conditions. As an 332 example, OA has been reported to exert an antioxidant effect through indirect biological 333 actions, as it was able to induce the expression of antioxidant enzymes such as glutathione 334 peroxidase, superoxide dismutase and catalase. ${ }^{22-26}$

335 Given that the concentrates and the pure TA were assayed at the same experimental 336 conditions, the results obtained in the antioxidant tests suggested that the slight antioxidant 337 activity found in the concentrates were not due to the TA. Other compounds could have been 338 involved instead. In this regard, phenolic compounds of strong antioxidant activities are 
339 known to be present in virgin olive oils. ${ }^{27}$ For this reason, the possible presence of phenolic 340 antioxidants in the TA concentrates was investigated. Preliminary assays gave positive results 341 in the Folin-Ciocalteu test (not shown), ${ }^{28}$ indicating the occurrence of phenolic compounds in

342 the TA concentrates. Thus, a detailed analysis of phenolic compounds was carried out for 343 characterization purposes. Results showed the presence of phenolic antioxidants at a 344 concentration range of $\mathrm{g} \mathrm{kg}^{-1}$ sample in all concentrates (Table 4). Samples C presented 345 greater levels of $p$-Coumaric acid, Luteolin and Apigenin and less contents of 346 Hydroxytyrosol-1-glucose and Vanillic acid than their S sample homologs. The levels of 347 Hydroxytyrosol were variable, being higher in the $\mathrm{C}$ samples than in their $\mathrm{S}$ sample 348 counterparts in the first harvest and lower in the following one. Tyrosol however showed a 349 definite trend to be more concentrated in the $\mathrm{S}$ samples.

350 The total levels of phenolic compounds were examined to determine whether the results 351 obtained in the antioxidant tests were mainly due to the action of phenolic antioxidants. The 352 total levels of phenols were similar between the $\mathrm{C}$ and their $\mathrm{S}$ sample homologs in the first 353 season, although statistical different at the beginning and the end of the harvest. In contrast, 354 remarkable differences were found in the second harvest. The S samples showed quite higher 355 total levels of phenolic compounds. These results were consistent with the levels of phenolic 356 compounds found for crude olive pomace oils in a previous report. ${ }^{2}$ Those extracted with 357 hexane presented significantly higher contents than those obtained by centrifugation. The 358 similar levels of phenolic compounds found for the $\mathrm{C}$ and their S sample counterparts in the 359 first season were consistent with the similar activities found in the antioxidant tests and with 360 the fact that definite patterns for the $\mathrm{C}$ and $\mathrm{S}$ samples were not found. In contrast, the higher 361 levels found for the S samples in the second season did not give rise to definite antioxidant 362 patterns for the $\mathrm{C}$ and $\mathrm{S}$ sample homologs. Nevertheless, the total levels of phenols were 
coherent with the antioxidant activity losses observed along each season and with the greater antioxidant activities found in the second harvest (Table 4).

The decrease of phenolic compounds found in the concentrates along each harvest may be related to the decreased contents in the fruit during ripening. ${ }^{29}$ In addition, the lower levels of phenols found in the concentrates of the first harvest could be associated to losses during the storage of the crude oils before being filtered. Unlike the oils of the second harvest, which were used immediately as they were received, the oils of the first season had been stored at refrigeration conditions for one year when they were filtered.

371 It is known that the phenolic compounds of greater antioxidant activity are those with two hydroxyl groups in ortho- position, the so called ortho-diphenols. ${ }^{30}$ The levels of $o$-diphenols were also examined to try to relate them with the results obtained in the antioxidant tests. The $o$-diphenols were formed by Hydroxytyrosol and its derivatives, and Luteolin. Their contents

375 followed a similar trend to that found for the total levels of phenolic compounds, except that the C samples of the first harvest showed significantly greater contents than their S sample counterparts (not shown). Therefore, the contents of $o$-diphenols did not provide additional or complementary information to the total levels of phenolic compounds.

A statistical analysis of linear correlation showed high, positive correlation coefficients

380 between the total amount of phenolic compounds and the DPPH and ABTS tests, respectively 381 (Table 5). The linear relationship found for the total phenols and the FRAP was moderate, whereas that with the ORAC assay was weak.

\section{CONCLUSIONS}

384 Results have shown that concentrates of TA, containing MA and OA, can be readily obtained 385 from a byproduct generated by filtration of crude olive pomace oils extracted by 386 centrifugation or with hexane. Concentrates isolated from oils obtained by centrifugation were 
387 rich in MA, whereas those from oils extracted with hexane were rich in OA. The concentrates

388 showed slight antioxidant properties that can be mainly attributed to the presence of phenolic 389 compounds at levels of $\mathrm{g} \mathrm{kg}^{-1}$ sample. 
392 This work was funded by the Spanish Ministry of Economy, Industry and Competitiveness 393 through project AGL2013-45110-R. We would also like to thank "Oleícola El Tejar" for 394 providing the oils, Irene Pérez de la Rosa for technical assistance, Concepción Romero 395 Barranco for the HPLC analyses of TA and phenolic compounds and José Julián Ríos Martín 396 for the GC-MS analysis. 
3991 Sánchez-Moral P and Ruiz-Méndez MV, Production of pomace olive oil. Grasas y $400 \quad$ Aceites 57:47-55 (2006).

4012 García A, Brenes M, Dobarganes MC, Romero C and Ruiz-Méndez MV, Enrichment of 402 pomace olive oil in triterpenic acids during storage of "Alpeorujo" olive paste. Eur $J$ 403 Lipid Sci Technol 110:1136-1141 (2008).

4043 Romero C, Medina E, Mateo MA and Brenes M, New by-products rich in bioactive 405 substances from the olive oil mill processing. J Sci Food Agric 98:225-230 (2018).

4064 Sánchez-Quesada C, López-Biedma A, Warleta F, Campos M, Beltrán G and Gaforio JJ, 407 Bioactive properties of the main triterpenes found in olives, virgin olive oil, and leaves of 408 Olea europaea. J Agric Food Chem 61:12173-12182 (2013).

4095 Rufino-Palomares EE, Pérez-Jiménez A, Reyes-Zurita FJ, García-Salguero L, Mokhtari 410 K, Herrera-Merchán A, Medina PP, Peragón J and Lupiáñez JA, Anti-cancer and anti411 angiogenic properties of various natural pentacyclic tri-terpenoids and some of their $412 \quad$ chemical derivatives. Curr Org Chem 19:919-947 (2015).

4136 Juan ME and Planas JM, Bioavailability and metabolism of maslinic acid, a natural 414 pentacyclic triterpene, in Recent Advances in Pharmaceutical Sciences VI, ed. by Muñoz415 Torrero D, Domínguez A and Manresa A. Research Signpost, pp. 131-145 (2016).

4167 Fukumitsu S, Kinoshita T, Villareal MO, Aida K, Hino A and Isoda H, Maslinic acid 417 improves quality of life by alleviating joint knee pain in the elderly: results from a 418 community-based pilot study. J Clin Biochem Nutr 61:67-73 (2017).

4198 Perez-Camino MC and Cert A, Quantitative determination of hydroxy pentacyclic 420 triterpene acids in vegetable oils. J Agric Food Chem 47:1558-1562 (1999).

4219 Ruiz-Méndez MV and Dobarganes MC, Olive oil and olive pomace oil refining. $O C L-O l$ 422 Corps Gras Lipides 6:56-60 (1999). 
10 Ruiz-Méndez MV, Dobarganes MC and Sánchez-Moral P, Edible olive pomace oil concentrated in triterpenic acids, procedure of physical refining utilized for obtainment thereof and recovery of functional components present in the crude oil. Patent ES 2332977 (A1) (2010).

11 Balanehru S and Nagarajan B, Protective effect of oleanolic acid and ursolic acid against lipid peroxidation. Biochem Int 24:981-990 (1991).

12 Montilla MP, Agil A, Navarro MC, Jiménez MI, García-Granados A, Parra A and Cabo MM, Antioxidant activity of maslinic acid, a triterpene derivative obtained from Olea europaea. Planta Med 69:472-474 (2003).

13 Perona JS, Arcemis C, Ruiz-Gutierrez V and Catalá A, Effect of dietary high-oleic-acid oils that are rich in antioxidants on microsomal lipid peroxidation in rats. $J$ Agric Food Chem 53:730-735 (2005).

14 Allouche Y, Warleta F, Campos M, Sánchez-Quesada C, Uceda M, Beltrán G and Gaforio JJ, Antioxidant, antiproliferative, and pro-apoptotic capacities of pentacyclic triterpenes found in the skin of olives on MCF-7 human breast cancer cells and their effects on DNA damage. J Agric Food Chem 59:121-130 (2011).

15 Allouche Y, Beltrán G, Gaforio JJ, Uceda M, and Mesa MD, Antioxidant and antiatherogenic activities of pentacyclic triterpenic diols and acids. Food Chem Toxicol 48:2885-2890 (2010).

16 Diaz AM, Abad MJ, Fernandez L, Recuero C, Villaescusa L, Silvan AM and Bermejo P, In vitro anti-inflammatory activity of iridoids and triterpenoid compounds isolated from Phillyrea latifolia L. Biol Pharm Bull 23:1307-1313 (2000). radical scavenging and $\alpha$-glucosidase inhibition, two potential mechanisms involved in the anti-diabetic activity of oleanolic acid. Grasas y Aceites 67:e142 (2016). 
18 Morales FJ, Martin S, Açar ÖÇ, Arribas-Lorenzo G and Gökmen V, Antioxidant activity of cookies and its relationship with heat-processing contaminants: a risk/benefit approach. Eur Food Res Technol 228:345-354 (2009).

19 Romero C, Medina E, Mateo MA and Brenes M, Quantification of bioactive compounds in Picual and Arbequina olive leaves and fruit. J Sci Food Agric 97:1725-1732 (2017).

20 Dobarganes MC, Velasco J and Dieffenbacher A, Determination of polar compounds, polymerized and oxidized triacylglycerols, and diacylglycerols in oils and fats. Pure Appl Chem 72:1563-1575 (2000).

21 Schaich KM, Tian X and Xie J, Reprint of "Hurdles and pitfalls in measuring antioxidant efficacy: A critical evaluation of ABTS, DPPH, and ORAC assays". J Funct Foods 18:782-796 (2015).

$22 \mathrm{Du} \mathrm{Y}$ and Ko KM, Oleanolic acid protects against myocardial ischemia-reperfusion injury by enhancing mitochondrial antioxidant mechanism mediated by glutathione and Q-tocopherol in rats. Planta Med 72:222-227 (2006).

23 Tsai SJ and Yin MC, Antioxidative and anti-inflammatory protection of oleanolic acid and ursolic acid in PC12 cells. J Food Sci 73:H174-H178 (2008).

24 Gao D, Li Q, Li Y, Liu Z, Fan Y, Liu Z, Zhao H, Li J and Han Z, Antidiabetic and antioxidant effects of oleanolic acid from Ligustrum lucidum Ait in alloxan-induced diabetic rats. Phytother Res 23:1257-1262 (2009).

46725 Cheng K, Liu J, Sun H and Xie J, Synthesis of oleanolic acid dimers as inhibitors of 468 glycogen phosphorylase. Chem Biodivers 7:690-697(2010).

26 Castellano JM, Guinda A, Delgado T, Rada M and Cayuela JA, Biochemical basis of the antidiabetic activity of oleanolic acid and related pentacyclic triterpenes. Diabetes 62:1791-1799 (2013). 
47227 Alu'datt MH, Rababah T, Alhamad MN, Al-Mahasneh MA, Almajwal A, Gammoha S,

473 Ereifej K, Johargy A and Alli I, A review of phenolic compounds in oil-bearing plants:

474 Distribution, identification and occurrence of phenolic compounds. Food Chem 218:99-

$475106(2017)$.

47628 Singleton VL, Orthofer R and Lamuela-Raventos RM, Analysis of total phenols and 477 other oxidation substrates and antioxidants by means of the Folin-Ciocalteau reagent. $478 \quad$ Methods Enzymol 299:152-178 (1999).

47929 Yousfi K, Cert RM and García JM, Changes in quality and phenolic compounds of virgin 480 olive oils during objectively described fruit maturation. Eur Food Res Technol 223:117$481 \quad 124(2006)$.

48230 Mateos R, Domínguez MM, Espartero JL and Cert A, Antioxidant effect of phenolic 483 compounds, $\alpha$-tocopherol, and other minor components in virgin olive oil. J Agric Food $484 \quad$ Chem 51:7170-7175 (2003). 


\section{$486 \quad$ Figure captions}

487 Figure 1. Evaluation of antioxidant activity of TA concentrates expressed as Trolox 488 Equivalent Antioxidant Capacity (TEAC). For sample names see Table 1. Different letters for 489 a given pair of $\mathrm{C}$ and $\mathrm{S}$ samples obtained from oils produced in a given season period denote 490 significant differences $(p<0.05)$.

491 
Table 1 Results of oil filtration and extraction of triterpenic acids (TA).

\begin{tabular}{lccccc}
\hline Samples & $\begin{array}{c}\text { Oil } \\
(\mathbf{g})\end{array}$ & $\begin{array}{c}\text { Oil retained } \\
(\mathbf{g})\end{array}$ & $\begin{array}{c}\text { Extract } \mathbf{1} \\
\mathbf{( g )}\end{array}$ & $\begin{array}{c}\text { Extract 2 } \\
(\mathbf{g})\end{array}$ & $\begin{array}{c}\text { Extract 2 } \\
(\mathbf{g ~ k g} \mathbf{~} \mathbf{0 i l})\end{array}$ \\
\hline $\mathbf{1 C}$ & 874.0 & 58.1 & 57.4 & 2.2 & 2.5 \\
$\mathbf{1 S}$ & 829.0 & 137.7 & 135.6 & 1.8 & 2.2 \\
$\mathbf{2 C}$ & 824.8 & 141.0 & 139.1 & 4.4 & 5.3 \\
$\mathbf{2 S}$ & 787.7 & 227.6 & 226.1 & 2.2 & 2.8 \\
$\mathbf{3 C}$ & 853.3 & 249.4 & 209.7 & 33.6 & 39.4 \\
$\mathbf{3 S}$ & 859.1 & 174.3 & 175.2 & 1.3 & 1.5 \\
$\mathbf{4 C}$ & 797.7 & 179.1 & 174.0 & 5.1 & 6.4 \\
$\mathbf{4 S}$ & 831.7 & 183.4 & 183.2 & 2.5 & 3.0 \\
$\mathbf{5 C}$ & 793.2 & 217.2 & 209.2 & 11.8 & 14.9 \\
$\mathbf{5 S}$ & 819.8 & 180.8 & 179.8 & 1.0 & 1.2 \\
$\mathbf{6 C}$ & 807.7 & 262.7 & 230.5 & 39.1 & 48.4 \\
$\mathbf{6 S}$ & 818.2 & 132.2 & 131.1 & 1.8 & 2.2 \\
\hline
\end{tabular}

1, January 13; 2, April 13; 3, May 13; 4, December 13; 5, March 14; 6, June 14; C, extract obtained from the oil produced by Centrifugation; $\mathbf{S}$, extract obtained from the oil produced by subsequent Solvent extraction; Oil retained, oil retained in the paper filter after filtration; Extract 1, oil retrieved in the washing step with hexane; Extract 2, concentrate of TA obtained by subsequent extraction with ethanol. 
Table 2 Quantitative analysis of triterpenic acids in the TA concentrates.

\begin{tabular}{lccc}
\hline Samples & $\mathbf{O A}\left(\mathbf{g ~ k g}^{-\mathbf{1}} \mathbf{~ s a m p l e}\right)$ & $\mathbf{M A}\left(\mathbf{g ~ k g}^{-\mathbf{1}} \mathbf{~ s a m p l e}\right)$ & Total $\left(\mathbf{g ~ k g}^{\mathbf{- 1}} \mathbf{~ s a m p l e}\right)$ \\
\hline $\mathbf{1 C}$ & $316 \pm 14$ & $575 \pm 19$ & $891 \pm 33$ \\
$\mathbf{1 S}$ & $451 \pm 11$ & $98 \pm 1$ & $549 \pm 13$ \\
$\mathbf{2 C}$ & $296 \pm 25$ & $678 \pm 7$ & $974 \pm 23$ \\
$\mathbf{2 S}$ & $548 \pm 35$ & $191 \pm 9$ & $738 \pm 35$ \\
$\mathbf{3 C}$ & $292 \pm 7$ & $687 \pm 7$ & $980 \pm 12$ \\
$\mathbf{3 S}$ & $544 \pm 12$ & $209 \pm 8$ & $753 \pm 20$ \\
$\mathbf{4 C}$ & $273 \pm 3$ & $646 \pm 7$ & $919 \pm 10$ \\
$\mathbf{4 S}$ & $405 \pm 30$ & $110 \pm 3$ & $515 \pm 31$ \\
$\mathbf{5 C}$ & $250 \pm 4$ & $698 \pm 18$ & $948 \pm 21$ \\
$\mathbf{5 S}$ & $703 \pm 19$ & $152 \pm 5$ & $855 \pm 23$ \\
$\mathbf{6 C}$ & $231 \pm 4$ & $624 \pm 2$ & $856 \pm 5$ \\
$\mathbf{6 S}$ & $632 \pm 9$ & $268 \pm 5$ & $900 \pm 14$ \\
\hline & & & \\
\hline
\end{tabular}

OA, Oleanolic acid; MA, Maslinic acid. See Table 1 for other abbreviations. Results are expressed as mean values followed by the standard deviation of three analytical determinations. 
Table 3 HPSEC analysis of the TA concentrates.

\begin{tabular}{|c|c|c|c|c|c|}
\hline Samples & $\begin{array}{c}\text { TAG } \\
\left(\mathrm{g} \mathrm{kg}^{-1} \text { sample }\right)\end{array}$ & $\begin{array}{c}\text { DAG } \\
\left(\mathrm{g} \mathrm{kg}^{-1} \text { sample }\right)\end{array}$ & $\begin{array}{c}\text { MAG } \\
\left(\mathrm{g} \mathrm{kg}^{-1} \text { sample) }\right.\end{array}$ & $\begin{array}{c}\text { FFA* } \\
\left(\mathrm{g} \mathrm{kg}^{-1} \text { sample }\right)\end{array}$ & $\begin{array}{c}\text { Oil } \\
\left(\mathrm{g} \mathrm{kg}^{-1} \text { sample }\right)\end{array}$ \\
\hline $1 \mathrm{C}$ & 23 & 22 & 7 & 948 & 52 \\
\hline $1 S$ & 193 & 31 & 16 & 760 & 240 \\
\hline $2 \mathrm{C}$ & 5 & 19 & 5 & 971 & 29 \\
\hline $2 S$ & 22 & 10 & 7 & 961 & 39 \\
\hline 3C & 12 & 18 & 3 & 967 & 33 \\
\hline $3 S$ & 10 & 17 & 6 & 967 & 33 \\
\hline $4 C$ & 31 & 22 & 5 & 942 & 58 \\
\hline $4 S$ & 10 & nd & nd & 990 & 10 \\
\hline $5 \mathrm{C}$ & 29 & 15 & 4 & 952 & 48 \\
\hline $5 S$ & 35 & 17 & nd & 948 & 52 \\
\hline $6 \mathrm{C}$ & 77 & 27 & 4 & 892 & 108 \\
\hline $6 S$ & 53 & 13 & 4 & 930 & 70 \\
\hline
\end{tabular}

TAG, Triacylglycerols; DAG, Diacylglycerols; MAG, monoacylglycerols; FFA*, group of compounds that normally comprises free fatty acids and other oil minor components in oil HPSEC analyses but it is mainly constituted by triterpenic acids in the analysis of the TA concentrates studied; Oil, obtained from the sum of TAG, DAG and MAG; nd, not detected. See Table 1 for other abbreviations. Results express mean values of two analytical determinations. 
Table 4 Analysis of phenolic compounds $\left(\mathrm{g} \mathrm{kg}^{-1}\right.$ sample) in the TA concentrates.

\begin{tabular}{|c|c|c|c|c|c|c|c|c|c|c|}
\hline Samples & Hy & Hy1G & Sa & $\mathbf{T y}$ & $\mathbf{V A}$ & $p-\mathrm{CoA}$ & Lut & Apig & Others* & Total \\
\hline $1 \mathrm{C}$ & $\begin{array}{l}3.42 \\
\pm 0.13\end{array}$ & $\begin{array}{l}0.064 \\
\pm 0.000\end{array}$ & $\begin{array}{l}0.037 \\
\pm 0.002\end{array}$ & $\begin{array}{l}0.59 \\
\pm 0.01\end{array}$ & $\begin{array}{l}0.037 \\
\pm 0.000\end{array}$ & $\begin{array}{l}0.136 \\
\pm 0.010\end{array}$ & $\begin{array}{l}0.229 \\
\pm 0.007\end{array}$ & $\begin{array}{l}0.076 \\
\pm 0.000\end{array}$ & $\begin{array}{l}0.047 \\
\pm 0.002\end{array}$ & $\begin{array}{l}4.63 \\
\pm 0.16\end{array}$ \\
\hline $1 S$ & $\begin{array}{l}3.00 \\
\pm 0.15\end{array}$ & $\begin{array}{l}0.150 \\
\pm 0.005\end{array}$ & $\begin{array}{l}0.081 \\
\pm 0.005\end{array}$ & $\begin{array}{l}0.73 \\
\pm 0.04\end{array}$ & $\begin{array}{l}0.087 \\
\pm 0.005\end{array}$ & $\begin{array}{l}0.015 \\
\pm 0.001\end{array}$ & $\begin{array}{l}0.032 \\
\pm 0.004\end{array}$ & nd & nd & $\begin{array}{l}4.10 \\
\pm 0.20\end{array}$ \\
\hline $2 \mathrm{C}$ & $\begin{array}{l}1.79 \\
\pm 1.12\end{array}$ & $\begin{array}{l}0.033 \\
\pm 0.003\end{array}$ & nd & $\begin{array}{l}0.41 \\
\pm 0.01\end{array}$ & $\begin{array}{l}0.029 \\
\pm 0.002\end{array}$ & $\begin{array}{l}0.061 \\
\pm 0.002\end{array}$ & $\begin{array}{l}0.232 \\
\pm 0.017\end{array}$ & $\begin{array}{l}0.070 \\
\pm 0.004\end{array}$ & $\begin{array}{l}0.010 \\
\pm 0.01\end{array}$ & $\begin{array}{l}2.64 \\
\pm 0.16\end{array}$ \\
\hline $2 S$ & $\begin{array}{l}0.26 \\
\pm 0.03\end{array}$ & $\begin{array}{l}0.048 \\
\pm 0.001\end{array}$ & nd & $\begin{array}{l}2.28 \\
\pm 0.14\end{array}$ & $\begin{array}{l}0.178 \\
\pm 0.015\end{array}$ & $\begin{array}{l}0.015 \\
\pm 0.000\end{array}$ & $\begin{array}{l}0.012 \\
\pm 0.002\end{array}$ & nd & nd & $\begin{array}{l}2.80 \\
\pm 0.19\end{array}$ \\
\hline 3C & $\begin{array}{l}0.94 \\
\pm 0.02\end{array}$ & nd & nd & $\begin{array}{l}0.23 \\
\pm 0.03\end{array}$ & nd & $\begin{array}{l}0.051 \\
\pm 0.006\end{array}$ & $\begin{array}{l}0.159 \\
\pm 0.013\end{array}$ & $\begin{array}{l}0.026 \\
\pm 0.001\end{array}$ & nd & $\begin{array}{l}1.41 \\
\pm 0.04\end{array}$ \\
\hline $3 S$ & nd & nd & nd & $\begin{array}{l}1.87 \\
\pm 0.12\end{array}$ & $\begin{array}{l}0.220 \\
\pm 0.031\end{array}$ & nd & nd & nd & nd & $\begin{array}{l}2.09 \\
\pm 0.16\end{array}$ \\
\hline $4 C$ & $\begin{array}{l}4.04 \\
\pm 0.60\end{array}$ & $\begin{array}{l}1.077 \\
\pm 0.312\end{array}$ & $\begin{array}{l}0.106 \\
\pm 0.027\end{array}$ & $\begin{array}{l}0.78 \\
\pm 0.07\end{array}$ & $\begin{array}{l}0.044 \\
\pm 0.004\end{array}$ & $\begin{array}{l}0.052 \\
\pm 0.011\end{array}$ & $\begin{array}{l}0.262 \\
\pm 0.067\end{array}$ & $\begin{array}{l}0.023 \\
\pm 0.004\end{array}$ & $\begin{array}{l}0.31 \\
\pm 0.05\end{array}$ & $\begin{array}{l}6.70 \\
\pm 1.16\end{array}$ \\
\hline $4 S$ & $\begin{array}{l}4.50 \\
\pm 0.01\end{array}$ & $\begin{array}{l}4.733 \\
\pm 0.020\end{array}$ & $\begin{array}{l}0.611 \\
\pm 0.009\end{array}$ & $\begin{array}{l}0.64 \\
\pm 0.03\end{array}$ & $\begin{array}{l}0.043 \\
\pm 0.004\end{array}$ & $\begin{array}{l}0.012 \\
\pm 0.001\end{array}$ & nd & nd & $\begin{array}{l}0.74 \\
\pm 0.11\end{array}$ & $\begin{array}{l}11.27 \\
\pm 0.09\end{array}$ \\
\hline $5 \mathrm{C}$ & $\begin{array}{l}0.27 \\
\pm 0.03\end{array}$ & nd & nd & $\begin{array}{l}0.66 \\
\pm 0.05\end{array}$ & $\begin{array}{l}0.045 \\
\pm 0.007\end{array}$ & $\begin{array}{l}0.054 \\
\pm 0.009\end{array}$ & $\begin{array}{l}0.206 \\
\pm 0.031\end{array}$ & $\begin{array}{l}0.031 \\
\pm 0.027\end{array}$ & nd & $\begin{array}{l}1.27 \\
\pm 0.06\end{array}$ \\
\hline $5 S$ & $\begin{array}{l}3.72 \\
\pm 0.04\end{array}$ & $\begin{array}{l}1.154 \\
\pm 0.064\end{array}$ & $\begin{array}{l}0.089 \\
\pm 0.021\end{array}$ & $\begin{array}{l}1.92 \\
\pm 0.05\end{array}$ & $\begin{array}{l}0.191 \\
\pm 0.004\end{array}$ & nd & nd & nd & $\begin{array}{l}0.13 \\
\pm 0.01\end{array}$ & $\begin{array}{l}7.21 \\
\pm 0.09\end{array}$ \\
\hline $6 C$ & $\begin{array}{l}0.89 \\
\pm 0.08\end{array}$ & nd & nd & $\begin{array}{l}0.41 \\
\pm 0.02\end{array}$ & $\begin{array}{l}0.032 \\
\pm 0.004\end{array}$ & nd & $\begin{array}{l}0.061 \\
\pm 0.053\end{array}$ & $\begin{array}{l}0.017 \\
\pm 0.015\end{array}$ & nd & $\begin{array}{l}1.41 \\
\pm 0.13\end{array}$ \\
\hline $6 S$ & $\begin{array}{l}0.91 \\
\pm 0.13\end{array}$ & nd & nd & $\begin{array}{l}1.09 \\
\pm 0.10\end{array}$ & $\begin{array}{l}0.088 \\
\pm 0.004\end{array}$ & nd & nd & nd & nd & $\begin{array}{l}2.09 \\
\pm 0.13\end{array}$ \\
\hline
\end{tabular}

Hy, Hydroxytyrosol; Hy1G, Hydroxytyrosol-1' $-\beta$-glucoside; Sa,Salidroside; Ty, Tyrosol; VA, Vanillic acid; $\boldsymbol{p}$ CoA, $p$-Coumaric acid; Lut, Luteolin; Apig, Apigenin; nd, not detected. See Table 1 for other abbreviations.*Hydroxytyrosol glycol, Hydroxytyrosol acetate, Caffeic acid and Comselogoside. Results are expressed as mean values followed by the standard deviation of three analytical determinations.

$o$-diphenols: Hydroxytyrosol, Hydroxytyrosol-1-glucose, Hydroxytyrosolglycol, Hydroxytyrosol acetate and Luteolin 
Table 5 Correlation coefficients found between the methods of antioxidant activity and the amounts of ortho-diphenols and total phenols.

\begin{tabular}{lcccccc}
\hline & $\begin{array}{c}\text { ortho- } \\
\text { diphenols }\end{array}$ & $\begin{array}{c}\text { Total } \\
\text { phenols }\end{array}$ & DPPH & ABTS & FRAP & ORAC \\
\hline ortho-diphenols & 1 & & & & & \\
Total phenols & 0.9727 & 1 & & & & \\
DPPH & 0.7450 & 0.6857 & 1 & & 1 & 1 \\
ABTS & 0.7893 & 0.8052 & 0.6968 & 1 & 0.4267 & 1 \\
FRAP & 0.5773 & 0.6462 & 0.5611 & 0.8547 & \\
ORAC & 0.3377 & 0.3345 & 0.4708 & 0.3113 & & \\
\hline
\end{tabular}

